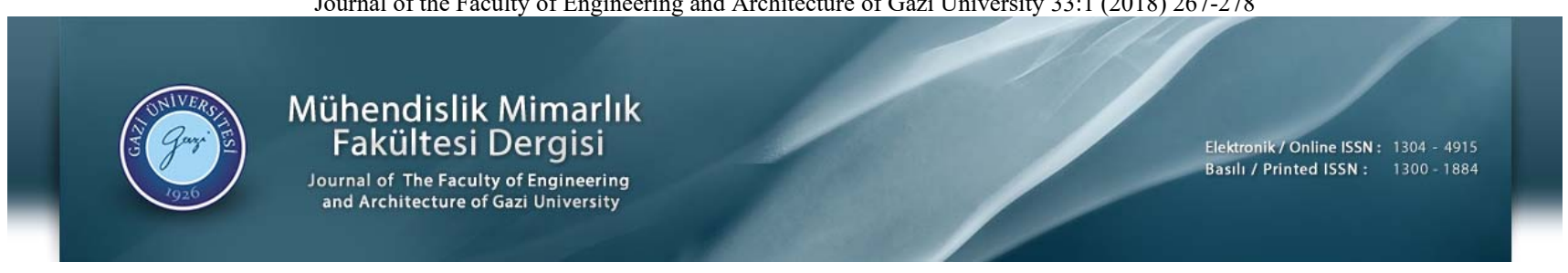

\title{
Yanıt yüzey yöntemi ile bir bor fabrikası atık suyu kimyasal arıtma sürecinde optimum koşulların belirlenmesi
}

Murat Bilen*(D), Çağlar Ateş (D), Bilal Bayraktar (D)

Eti Maden İșletmeleri Genel Müdürlüğ̈̈, Ankara, 06010, Türkiye

Ö N E Ç I K A N L A R

- Yanıt yüzey yöntemi ile bir atık su arıtım prosesinin istatiksel analizi

- Çöktürme ile atık sudan bor gideriminin optimizasyonu

- $\quad$ Çeşitli parametrelerin atık su arıtımı üzerine etkisi

Makale Bilgileri

Geliş: 31.10.2016

Kabul: 02.03.2017

DOI:

10.17341/gazimmfd.406798

Anahtar Kelimeler:

Borun uzaklaştırılması, atık su arıtımı,

yanıt yüzey yöntemi,

\section{ÖZET}

Bu çalışmada, Eti Maden işletmeleri Genel Müdürlüğü, Bandırma Bor ve Asit Fabrikaları İşletme Müdürlüğü atık suyunun derin deniz deşarj limitlerinin altına çekilmesi için kalsiyum hidroksit $\left(\mathrm{Ca}(\mathrm{OH})_{2}\right)$ kullanılarak borun giderilmesi yanıt yüzey yöntemi (RSM) aracılığıyla incelenmiştir. Başlangıç pH'ı, tepkime süresi, tepkime sıcaklığ ve $\% \mathrm{Ca}(\mathrm{OH})_{2} / \mathrm{B}_{2} \mathrm{O}_{3}$ oranı deney parametreleri olarak seçilmiştir. Yanıt yüzey yöntemi (RSM) merkezi bileşik tasarımı (CCD) önermiş ve önerilen kuadratik model, ANOVA sonuçlarına göre tasarım alanı için kullanılabilir deneysel verilere iyi uyum göstermiştir. Elde edilen bu veriler ışığında laboratuvar koşullarında atık sudaki bor miktarı ortalama $7006 \mathrm{mg} / \mathrm{L}$ ' den $487 \mathrm{mg} / \mathrm{L}$ ' e düşürülerek deşarj limit değerinin (Bor $<500 \mathrm{mg} / \mathrm{L})$ altına başarılı bir şekilde indirilmiştir. $\mathrm{pH}$

\section{Determination of optimal conditions in boron factory wastewater chemical treatment process via response surface methodolgy}

\section{H I G H L I G H T S}

- Statistical analysis of a waste water treatment process via response surface methodology

- Optimization of boron removal by precipitation in waste water

- The effect of various parameters on waste water treatment

Article Info

Received: 31.10 .2016

Accepted: 02.03.2017

DOI:

$10.17341 /$ gazimmfd.406798

Keywords:

Boron removal, wastewater treatment, response surface methodology, $\mathrm{pH}$

\begin{abstract}
In this study, an investigation study was undertaken to reduce the value of boron in Eti Mine Works General Directorate, Bandırma Boron and Acid Factory, in Turkey, wastewater under discharge limit by using Calcium hydroxide $\mathrm{Ca}(\mathrm{OH})_{2}$ via Response Surface Methodology (RSM) and initial $\mathrm{pH}$, reaction time, reaction temperature, and the ratio of $\mathrm{Ca}(\mathrm{OH})_{2} / \mathrm{B}_{2} \mathrm{O}_{3} \%$ were selected as experimental parameters. RSM proposed quadratic model for central composite design (CCD). The proposed quadratic model fit well to the experimental data that it could be used to navigate the design space according to ANOVA results. The obtained data showed that under laboratory conditions, the value of boron in wastewater was reduced succesfully under the discharge limit (Boron $<500 \mathrm{mg} / \mathrm{L}$ ) from average $7006 \mathrm{mg} / \mathrm{L}$ to $487 \mathrm{mg} / \mathrm{L}$.
\end{abstract}




\section{GİRIŞ (INTRODUCTION)}

Bor elementinin birçok minerali vardır. Ancak bunlar içerisinde hepsinin rezerv durumları farklıdır. Önemli bor mineralleri, boraks, kernit, üleksit, probertit, kolemanit, pandermit, hidroborasittir. Türkiye de bor madeni yatakları özellikle Kırka, Emet, Bigadiç, Kestelek' te bulunmaktadır [1]. Borun kullanım alanları arasında cam, seramik, temizlik, yarıiletken, ilaç ve kozmetik sektörleri sayılabilir [2]. Çinko borat gibi özel bor ürünleri, boyalarda yangın geciktirici olarak kullanılabilirken; elementel bor da sahip olduğu yüksek sertlik, yüksek ergime sıcaklığı, yüksek mukavemet, yüksek kimyasal direnç gibi özellikleri sayesinde birçok yerde kullanılabilmektedir [3, 4]. Bunlara ek olarak bor, bitkiler ve hayvanlar için temel bir mikro besleyici olup gelişimlerinde önemli bir rol oynar. Öte yandan gerekli miktarlardan fazla kullanılan her kimyasal gibi borun fazlasının da kullanılması durumunda bitkilere ve insanlara toksik etki gösterebilir. Dünya Sağlık Örgütü (WHO) uzun y1llar boyunca içme suyundaki bor limitini $0,3 \mathrm{mg} / \mathrm{L}$ olarak belirlemiştir. Ancak 2011 yılında borun insan sağlı̆̆ına etkilerinden ötürü bu değer $2,4 \mathrm{mg} / \mathrm{L}$ olarak revize edilmiştir [5]. Öte yandan AB içme suyundaki bor limitinin $1 \mathrm{mg} / \mathrm{L}$ olması gerektiğini söylemektedir [6]. Türk çevre mevzuatına göre ise denize deşarj edilecek sudaki bor miktarının 500 $\mathrm{mg} / \mathrm{L}$ 'i geçmemesi gerekmektedir [7].

Sudaki fazla bor miktarının her kimyasal gibi doğaya verebileceği muhtemel olumsuz etkilerin önüne geçebilmek için çeşitli su kaynaklarındaki bor miktarı kontrol altında tutulmalıdır ve bu nedenle günümüzde sulardan bor giderimi önemli bir araştırma konusu olmuştur. Bor bileşiklerinin antiseptik özelliğe sahip olmasından ötürü konvansiyonel biyolojik arıtma yöntemleri atık sudan bor gideriminde kullanılamamaktadır [8]. Ancak borun çeşitli sulardan giderilmesi konusunda literatürde; adsorpsiyon [9], iyon değiştirme [10], ters osmoz [11], elektrokoagülasyon [12, 13], elektrodiyaliz [14] ve $\mathrm{Ca}(\mathrm{OH})_{2}$ ile $\mathrm{MgO}$ kullanılarak yapılan çöktürme yöntemleriyle giderimine dair birçok çalışma yer almaktadır [8, 15]. Adsorpsiyon, elektrokoagülasyon ve elektrodiyaliz ile bor giderimine dair yapılan çalışmalarda başarılı sonuçlara ulaşılmakla beraber çoğunlukla düşük miktarda bor içeren sentetik çözeltilerle çalışılmıştır ve endüstride bu yöntemlerle arıtım kendisine geniş bir kullanım alanı şimdilik bulamamıştır. Adsorpsiyon ile bor giderim çalışmalarında şelatlayıcı reçineler, aktif karbon, uçucu kül gibi adsorbantlar kullanılarak \%99,8'e varan bor giderim verimlerine ulaşılmasına rağmen bu giderim verimlerine çok düşük derişimli bor çözeltilerinde ulaşılması ve kullanılan adsorbant miktarının tutulan bor miktarına oranının çok olması bu yöntemin endüstriyel anlamda uygulanabilirliği noktasındaki en büyük dezavantajıdır [9]. Elektrokoagülasyon ile bor giderim yöntemi son zamanlarda ortaya çıkmış yeni bir yöntem olup, temelde kimyasal koagülasyon ile aynı tepkimeler üzerinden gerçekleşmekte; ancak düşük çamur miktarı, çözeltiye fazladan anyon vermeme ve yüksek verim ile bor giderimi gibi avantajları ile dikkat çekmektedir [12].
Bu avantajlar sentetik çözeltiler için geçerli olmakla beraber gerçek çözeltilerde bu avantajlı durum ortadan kalkmakta ve özellikle endüstriyel uygulamalarda yüksek enerji sarfiyatlarından dolayı bor giderimi için uygun bir yöntem olmaktan çıkmaktadır $[12,13]$. Elektrodiyaliz yöntemi ile bor giderimi, düşük bor derişimlerine sahip sentetik çözeltilerde kısmen başarılı sonuçlar vermiştir [14]. Ancak gerçek çözeltilerde yüksek bor derişimi, yüksek iletkenlik ve diğer iyonların etkilerinden dolayı uygulama alanı oldukça kısitlidır ve genellikle ters osmoz ile arıtım proseslerinin temiz çıkış akımlarında son arıtım ünitesi olarak kullanılır. İyon değiştirme çalışmalarında \%90-98 aralığında bor giderimi verimleri elde edilmiştir ancak bu yöntemde de rejenarasyon maliyeti genel olarak önemli bir sorun olarak karşımıza çıkmaktadır [10]. Ters osmozla yapılan çalışmalarda giderim verimi ise ortalama \%63-82 olarak bulunmuş pH'ın 10,5'e çıkarılması ile verimin \%99'a kadar çıktığı görülmüştür. Ters osmoz yönteminde membranın stabilitesi, maliyeti ve membranın $\mathrm{CaCO}_{3}$ ile kaplanması gibi konular yöntemin etkinliği konusunda soru işaretleri oluşturmaktadır. Ayrıca bu yöntemde daha kirli bir atık akımı çıkmaktadır ve bununda bertaraf edilmesi ayrı bir problem teşkil etmektedir [11]. Çöktürme yöntemi ise basit, endüstriyel anlamda kolay kurulum, geniş uygulama alanı ve çöktürme sonucu ortaya çıkan bor içeren katı atığın çimento ve seramik endüstrilerinde hammadde olarak kullanılabilirliği ile öne çıkmaktadır $[8,15]$.

Literatürde bor içeren suyun ihtiva ettiği bor miktarına bağlı olarak uygun arıtım prosesinin seçilmesine dair genel bilgilere ulaşılabilmektedir. Çalışmalarda bor oksit $\left(\mathrm{B}_{2} \mathrm{O}_{3}\right)$ miktarının $25 \mathrm{~g} / \mathrm{L}$ 'den fazla $(\mathrm{B}>7850 \mathrm{mg} / \mathrm{L})$ olduğu durumlarda $\mathrm{Ca}(\mathrm{OH})_{2}, \mathrm{MgO},\left(\mathrm{NH}_{4}\right)_{2} \mathrm{CO}_{3}, \mathrm{Na}_{2} \mathrm{CO}_{3}$ gibi maddelerle borun çözünürlüğü düşük tuzları oluşturularak giderimi önerilmektedir [16]. Bor oksit $\left(\mathrm{B}_{2} \mathrm{O}_{3}\right)$ miktarının 1$3 \mathrm{~g} / \mathrm{L}$ arasında olduğu durumlarda $(315<\mathrm{B}<1000 \mathrm{mg} / \mathrm{L})$ $(\mathrm{M}(\mathrm{OH}) \mathrm{n}, \mathrm{M}=\mathrm{Al}, \mathrm{Fe}, \mathrm{Sn}, \mathrm{Ti}, \mathrm{Mn}, \mathrm{Ni}, \mathrm{Mg}, \mathrm{Zn}, \mathrm{Zr}$ vb. sorbentler ya da iyon değiştirici reçineler ile giderim yöntemlerinin kullanılabileceğinden bahsedilmektedir [17]. Son olarak $\mathrm{B}_{2} \mathrm{O}_{3}$ miktarının $1 \mathrm{~g} / \mathrm{L}$ den daha az durumlarda ise $(\mathrm{B}<315 \mathrm{mg} / \mathrm{L})$ son zamanlarda çeşitli membran ya da elektrokimyasal yöntemlerle borun giderilebileceğine dair çalışmalara ulaşıllabilmektedir [18].

\subsection{Yanıt Yüzey Yöntemi ve Deney Tasarımı \\ (Response Surface Method and Experimental Design)}

Çalışmada kullanılan yanıt yüzey yöntemi (RSM) ise istenen yanıtın çeşitli değişkenlerden etkilendiği ve bu yanıtın optimize edilmesinin amaçlandığı uygulamalarda modelleme ve analizleme için kullanılan matematiksel ve istatistiksel tekniklerin toplanmış halidir. $\mathrm{Bu}$ yöntem özellikle kimya mühendisliğinde proses ve deney tasarımlarında en az deney sayısıyla en uygun cevaba ulaşılmasını sağladığ kullanılmaktadır. Çevre mühendisliği uygulamalarında da yine yanıt yüzey yöntemi (RSM) sulardan çeşitli kirleticilerin uzaklaştırılmasını incelemek için güvenilir bir yöntem olarak görülüp, kullanılmaktadır [19, 20]. 
RSM, kontrollü deneysel bağımsız faktörler ve bir ya da birden çok seçilmiş kıstasa göre ölçülmüş yanıtlar (bağımlı değişkenler) arasındaki ilişkiyi bulmak için bir grup deneysel tekniği içermektedir [21]. Sürecin optimize edilmesi için etkili bir yöntem olan RSM en küçük kareler yöntemine uyan "Central Composite Design, merkezi bileşik tasarımı" gibi deneysel tasarımları kullanır. Eğer varyans analizi (ANOVA) ile test edilmiş önerilen model uygun ise, çalışılan bağımsız değişken aralıklarında yanıt değerlerini incelemek ve optimizasyon çalışmaları yapmak için kullanılabilmektedir. Merkezden bütün yönlere eşit öngörülebilirliği sahip CCD, RSM'de kullanılan en yaygın deneysel tasarımdır ve bu çalışmada da kullanılmıştır. Merkezi bileşik tasarımına (CCD) göre, toplam kombinasyon sayıs1, $2^{k}+2 k+n 0$ 'dır. Burada $k(k=4)$ bağımsız değişkenleri ve $n 0 \quad(n 0=6)$ sayısı merkez noktasındaki deneylerin tekrar sayısını göstermektedir [22]. Bu çalışmada ilk defa gerçek bir bor fabrika atık suyundan bor giderimi kimyasal çöktürme yöntemi ile çalışılmış ve Türk çevre mevzuatına göre deşarj edilebilir su üretilmesi amaçlanmıştır. Bu amaca ulaşmak içinde yine ilk kez bir kimyasal çöktürme prosesinin optimizasyonu için deneysel verileri kullanarak yanıt yüzey yöntemi (RSM) ile başlangıç pH'1, tepkime süresi, tepkime sıcaklığ 1 ve $\% \mathrm{Ca}(\mathrm{OH})_{2} / \mathrm{B}_{2} \mathrm{O}_{3}$ oranının $\%$ Bor giderimi miktarı üzerine etkileri incelenmiştir.

\section{DENEYSEL METOT (EXPERIMENTAL METHOD)}

\subsection{Malzeme (Material)}

Çalışmalarda kullanılan atık su çözeltisi Eti Maden İşletmeleri Genel Müdürlügüu, Bandırma Bor ve Asit Fabrikaları İşletme Müdürlüğü Tesislerindeki atık su havuzundan alınmıştır. Tablo 1'de özellikleri verilen atık su çözeltisi çalışma süresince 100 L'lik tankta muhafaza edilmiş ve çözeltinin homojen yapısını korunması amacıyla çöktürme deneyleri öncesi oda sicaklığında $\left(25 \pm 1^{\circ} \mathrm{C}\right), 30$ min süreyle, $250 \mathrm{rpm}$ dönme hızında sürekli karıştırma gerçekleştirilmiştir. Çöktürme deneylerinde kalsiyum hidroksit $\left(\mathrm{Ca}(\mathrm{OH})_{2}, \% 99\right.$, Merck) ve sülfürik asit $\left(\mathrm{H}_{2} \mathrm{SO}_{4}\right.$, \%95-98, Merck) kullanılmıştır.

\subsection{Deneysel Çalışmalar (Experimental Method)}

Deneysel çalışmalar şematik gösterimi Şekil 1' de verilen reaktör sisteminde gerçekleştirilmiştir. Aynı deney setinin aynı zaman ve koşulda iki kez tekrarlanmasını sağlamak ve deneysel hatalardan kaynaklanabilecek farkları en aza indirmek amaciyla sistemde birbirine paralel bağlı iki reaktör bulunmaktadır. Sistemde $150 \mathrm{rpm}$ karıştırıcıları bulunan reaktörlerin 1sitılması kriyostat yardımıyla gerçekleştirilmektedir.

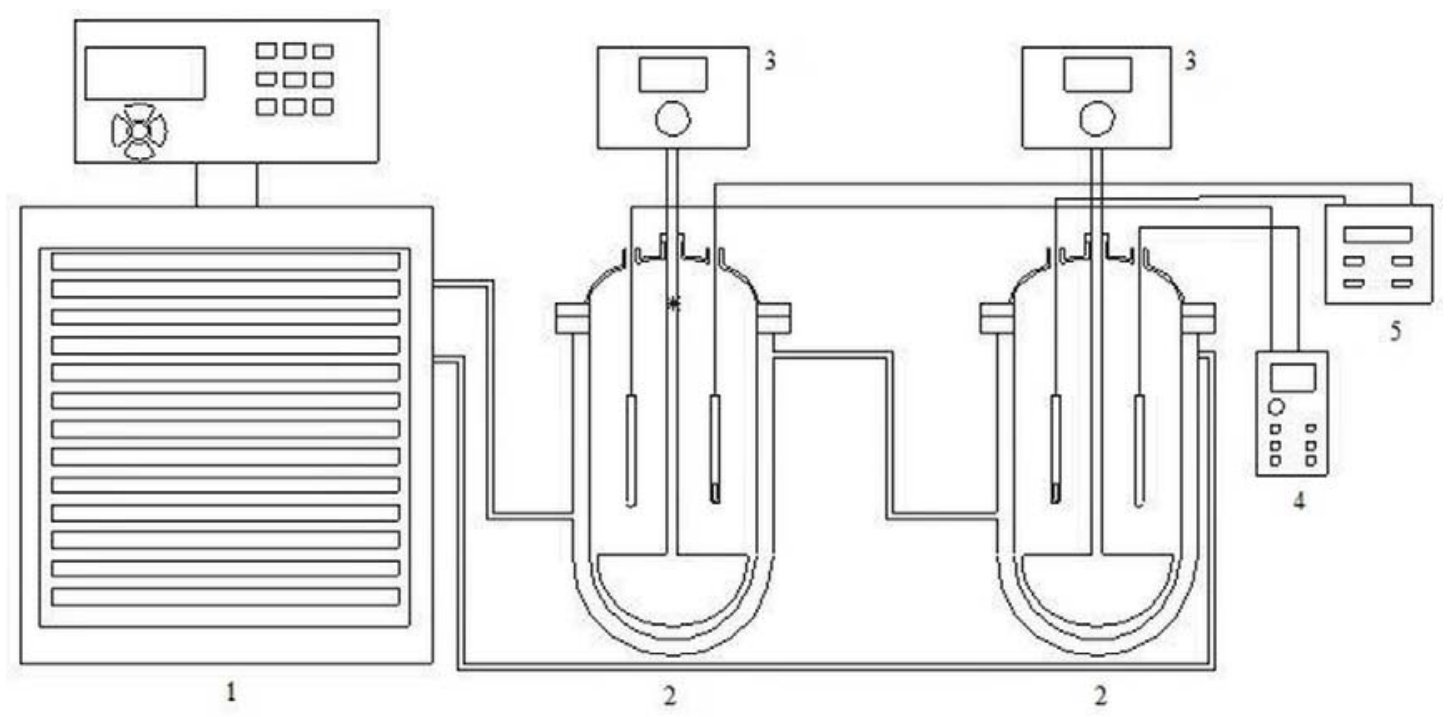

Şekil 1. Paralel bağlı reaktör sistemi (1: kriyostat 2: reaktör 3: karıştırıcı motor 4: termometre 5: pH metre) (Parallel reactor system (1: cryostat 2: reactor 3: stirrer motor 4: thermometer 5: $\mathrm{pH}$ meter))

Tablo 1. Atık suyun özellikleri (Properties of the waste water)

\begin{tabular}{llll}
\hline Özellik & \multirow{2}{*}{ Birim } & $\begin{array}{l}\text { Minimum-Maksimum } \\
\text { Değerler }\end{array}$ & $\begin{array}{l}\text { 30 Numunenin } \\
\text { Ortalama Değeri }\end{array}$ \\
\hline İlk pH & - & $8,5-8,9$ & 8,7 \\
İlk Sicaklık & ${ }^{\circ} \mathrm{C}$ & $24-26$ & 25 \\
Başlangıç B & $\mathrm{B} \mathrm{mg/L}$ & $6739-7274$ & 7006 \\
Derişimi & & $7438-8042$ & 7740 \\
Na Derişimi & $\mathrm{Na} \mathrm{mg/L}$ & $39-43$ & 42 \\
Ca Derişimi & $\mathrm{Ca} \mathrm{mg/L}$ & $47-55$ & 52 \\
Mg Derişimi & $\mathrm{Mg} \mathrm{mg} / \mathrm{L}$ & 47 & \\
\hline
\end{tabular}


Deneysel çalışmaların akış şeması Şekil 2'de verilmiştir. Deneylerde öncelikle $\mathrm{pH}$ ve B içerikleri belirlenen homojen çözeltilerden 500'er $\mathrm{ml}$ reaktörlere aktarılmıştır. Reaktörlerde 150 rpm karıştırma hızında çözeltiler deneyin yapılacağı sicaklığa kadar isitılmış ve bu sicaklıkta reaktörlere $\mathrm{H}_{2} \mathrm{SO}_{4}$ eklemesi yapılarak $\mathrm{pH}$ deneyin yapılacağ seviyeye getirilmiştir. Sonrasında çözeltilere $\mathrm{Ca}(\mathrm{OH})_{2}$ eklemesi yapılarak belirlenen sürelerde tepkime gerçekleştirilmiştir.

$\mathrm{Bu}$ sürenin sonunda dinlenmeye bırakılan çözelti oda sıcaklığına $\left(25 \pm 1^{\circ} \mathrm{C}\right)$ geldiğinde süzme işlemi ile katı sıv1 ayrımı gerçekleştirilmiş ve elde edilen sıvı numunelerin $\mathrm{B}_{2} \mathrm{O}_{3}$ analizleri yapılmıştır. Deneylerde çöktürme işlemi sonrasi alınan sıv1 numunelerin $\mathrm{B}_{2} \mathrm{O}_{3}$ analizleri, borik asit ile kompleks bir bileşik oluşturan manitol vasıtasıyla potansiyometrik olarak yapılmıştır. $\mathrm{Bu}$ amaçla, örnek filtrelendikten sonra çözelti pH'1 7,60'a ayarlanmış daha sonra çözeltiye $5 \mathrm{~g}$ manitol ilave edilmiş ve çözelti $\mathrm{pH}$ değeri 7,60 olana kadar $0,5 \mathrm{~N} \mathrm{KOH}$ ile titre edilmiştir. $\mathrm{B}_{2} \mathrm{O}_{3}$ miktarı $\mathrm{KOH}$ tüketiminden hesaplanmıştır. Bir mililitre $0,5 \mathrm{~N} \mathrm{KOH}$, $17,41 \mathrm{mg} \mathrm{B} \mathrm{O}_{3}{ }^{\prime} \mathrm{e}$ eşdeğerdir [23]. Numunelerin $\mathrm{B}$ içeriği ise analiz sonucunda elde edilen değerler 21,622/69,618 (2mol elementel $\mathrm{B}$ kütlesi/1mol $\mathrm{B}_{2} \mathrm{O}_{3}$ kütlesi) ile çarpılarak hesaplanmıştır. Tepkime sonucu elde edilen katı numune Memert/UN55 etüvde $4 \mathrm{~h}$ boyunca $105{ }^{\circ} \mathrm{C}$ sicaklikta kurutulmuş ve porselen havanda öğütülmüştür. Numunenin kalitatif analizi ise X-Işını Kırınımı (XRD) yöntemi ile PANalytical / Empyrean cihazında Co tüp kullanılarak yapılmıştır.

\subsection{Yanıt Yüzey Yöntemi ve Deney Tasarımı \\ (Response Surface Method and Experimental Design)}

Başlangıç pH'ı (A), tepkime süresi (B), tepkime sıcaklığg (C) ve $\% \mathrm{Ca}(\mathrm{OH})_{2} / \mathrm{B}_{2} \mathrm{O}_{3}$ oranının (D), $\% \mathrm{~B}$ giderim miktarı üzerinde önemli etkilere sahip olacağı öngörülerek bağımsız değişkenler olarak seçilmiştir. Laboratuvar koşullarında yapılmış olan ön çalışmalarda yine bu parametrelerin en önemli parametreler olduklarını göstermiştir. Seçilen her bağımsız değişken -1 ve +1 kodlanmış değerler aralığında tanımlanmıştır, bu çalışmada incelenen kodlamış ve gerçek değerler Tablo 2 'de gösterilmiştir. Sistemde bağımsız değişkenlerin yanıtı doğrusal ise yanıt fonksiyonu birinci dereceden verilmektedir. Ĕger sistemde doğrusallıktan uzaklaşma varsa yüksek dereceli polinomlar kullanılmaktadır (Eş. 1).

$Y=B_{0}+\sum_{t=1}^{n} B_{t} x_{t}+\sum_{t j} B_{t j} x_{t} x_{j}+\sum_{j=1}^{n} B_{j j} x_{j}^{2}$

Burada $Y$, tahmini yanıt olup dört değişken içermektedir ve dolayısıyla bu çalışmada $n 4$ değerini almaktadır. Polinom

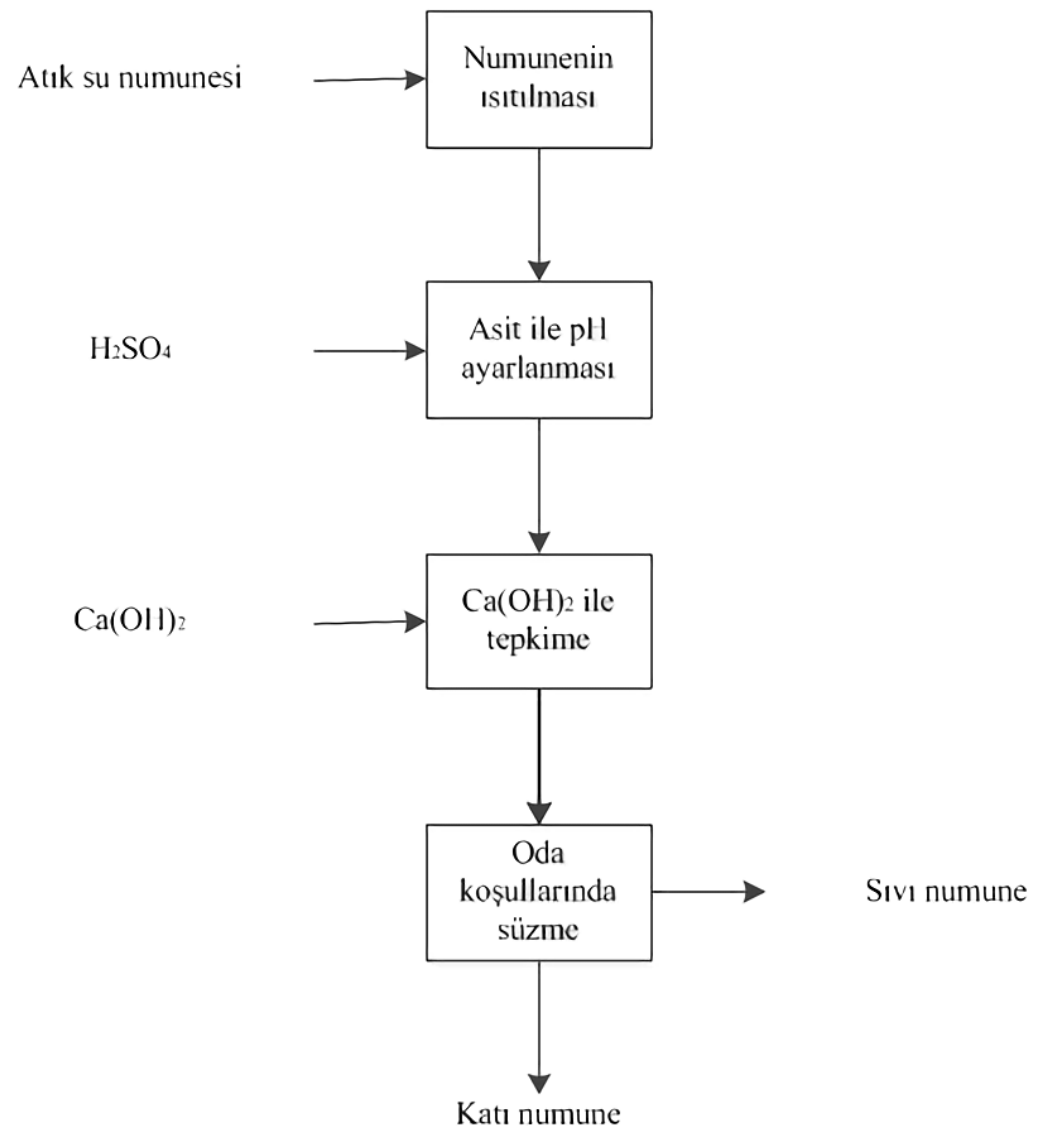

Şekil 2. Deneysel yöntem akım şeması (Experimental procedure flow chart) 
modelinin uygunluğu $\mathrm{R}^{2}$ katsayısı ile ifade edilmektedir [22] ve modelin istatistiksel anlamlılığ1 ve yeterliliği ise $\mathrm{F}$ değeri (F-Value- Fisher variation ratio), olasılık değeri (Prob $>$ Fprobability value ) ve uygun kesinlik (Adequate Precision) terimlerini içermektedir [24].

\section{SONUÇLAR VE TARTIŞMALAR (RESULTS AND DISCUSSIONS)}

Merkezi Bileşik Tasarım (CCD) deney tasarımıyla 30 adet deney yapılmış ve her deneyin çalışma koşulları ve yanıtı Tablo 3'te verilmiştir. \% Bor giderimi 1,89 ile 94,7 arasında bulunmuştur.

\subsection{ANOVA Varyans Analizi (Analysis of Variance ANOVA)}

Tablo 4'de bor giderimi için önerilen quadratik modelin varyans analizi (ANOVA) tablosu yer almaktadır. ANOVA tablosunda da görüldüğ̈̈ üzere modelin 24,33'lük F değeri (F-Value- Fisher variation ratio) ve düşük olasılık değeri (Prob $>$ F- probability value $<0,0001$ ) bor giderimi için modelin anlamlı olduğunu ifade etmektedir. 0,0500' den küçük olasılık değeri (Prob $>$ F- probability value $<0,0500$ ) modelin anlamlı olduğunu gösterirken, 0,1000'den büyük olması anlamsız olduğunu göstermektedir [25]. Sapmaya karşı verilen cevabın oranını gösteren uygun kesinlik

Tablo 2. Bağımsız değişkenlerin kodlanmış ve gerçek değerleri (Coded and real values of the independent variables)

\begin{tabular}{llllllll}
\hline Bağımsız değişkenler & \multicolumn{5}{c}{ Kodlanmıs ve Gerçek Değerler } \\
\hline Faktör & İsim & Birim & -2 & -1 & 0 & 1 & 2 \\
A & Başlangıc pH'1 & - & 2,25 & 4 & 5,75 & 7,5 & 9,25 \\
B & Zaman & min & 0 & 60 & 120 & 180 & 240 \\
C & Sicaklık & ${ }^{\circ} \mathrm{C}$ & 20 & 40 & 60 & 80 & 100 \\
$\mathrm{D}$ & $\% \mathrm{Ca}(\mathrm{OH})_{2} / \mathrm{B}_{2} \mathrm{O}_{3}$ & $\%(\mathrm{~g} / \mathrm{g})$ & 12,50 & 175 & 337,50 & 500 & 662,50 \\
\hline
\end{tabular}

Tablo 3. Farklı deney koşulları için yanıtlar (Responses for the different experimental conditions)

\begin{tabular}{|c|c|c|c|c|c|c|c|c|}
\hline Çalışma & $\begin{array}{l}\text { Başlangıç } \\
\text { pH'1 - (A) }\end{array}$ & $\begin{array}{l}\text { Süre } \\
\text { min } \\
\text { (B) }\end{array}$ & $\begin{array}{l}\text { Sicaklik } \\
{ }^{\circ} \mathrm{C}(\mathrm{C})\end{array}$ & $\begin{array}{l}\% \mathrm{Ca}(\mathrm{OH})_{2} / \mathrm{B}_{2} \mathrm{O}_{3} \\
\%(\mathrm{~g} / \mathrm{g})(\mathrm{D})\end{array}$ & $\begin{array}{l}\text { Son } \\
\mathrm{pH}-\end{array}$ & $\begin{array}{l}\text { Başlangıç } \\
\text { Bor } \\
\text { Miktarı } \\
(\mathrm{mg} / \mathrm{L})\end{array}$ & $\begin{array}{l}\text { Son } \\
\text { Bor } \\
\text { Miktar1 } \\
(\mathrm{mg} / \mathrm{L}) \\
\end{array}$ & $\begin{array}{l}\text { \%Bor } \\
\text { Giderimi } \\
\text { (Yanit) }\end{array}$ \\
\hline 1 & 7,5 & 180 & 40 & 500 & 12,1 & 6953 & 802 & 88,46 \\
\hline 2 & 9,25 & 120 & 60 & 337,5 & 12,2 & 6740 & 1471 & 78,17 \\
\hline 3 & 5,75 & 0 & 60 & 337,5 & 11,4 & 7167 & 1525 & 78,73 \\
\hline 4 & 7,5 & 60 & 40 & 500 & 11,9 & 7274 & 829 & 88,6 \\
\hline 5 & 5,75 & 120 & 60 & 337,5 & 12,1 & 7060 & 1113 & 84,23 \\
\hline 6 & 5,75 & 120 & 60 & 12,5 & 11,3 & 7060 & 6927 & 1,89 \\
\hline 7 & 4 & 180 & 40 & 500 & 12,2 & 7007 & 1230 & 82,45 \\
\hline 8 & 5,75 & 120 & 20 & 337,5 & 12,3 & 6920 & 749 & 89,18 \\
\hline 9 & 4 & 180 & 80 & 175 & 11,9 & 6900 & 1711 & 75,2 \\
\hline 10 & 5,75 & 120 & 60 & 337,5 & 12,1 & 7060 & 1106 & 84,33 \\
\hline 11 & 4 & 60 & 40 & 175 & 12,0 & 7274 & 1899 & 73,9 \\
\hline 12 & 4 & 180 & 80 & 500 & 11,8 & 6870 & 487 & 92,91 \\
\hline 13 & 5,75 & 120 & 60 & 337,5 & 12,1 & 6953 & 1264 & 81,82 \\
\hline 14 & 5,75 & 120 & 100 & 337,5 & 11,6 & 6867 & 364 & 94,7 \\
\hline 15 & 5,75 & 240 & 60 & 337,5 & 12,1 & 7060 & 508 & 92,8 \\
\hline 16 & 5,75 & 120 & 60 & 337,5 & 12,1 & 7167 & 1303 & 81,82 \\
\hline 17 & 7,5 & 60 & 80 & 500 & 11,9 & 7007 & 856 & 87,78 \\
\hline 18 & 4 & 180 & 40 & 175 & 12,0 & 7114 & 1685 & 76,31 \\
\hline 19 & 7,5 & 180 & 40 & 175 & 11,8 & 7167 & 1123 & 84,33 \\
\hline 20 & 4 & 60 & 80 & 175 & 11,7 & 7274 & 1659 & 77,2 \\
\hline 21 & 7,5 & 180 & 80 & 175 & 11,9 & 7060 & 2407 & 65,91 \\
\hline 22 & 2,25 & 120 & 60 & 337,5 & 11,7 & 7007 & 1149 & 83,6 \\
\hline 23 & 5,75 & 120 & 60 & 662,5 & 12,2 & 7007 & 883 & 87,4 \\
\hline 24 & 5,75 & 120 & 60 & 337,5 & 12,1 & 7060 & 1284 & 81,82 \\
\hline 25 & 5,75 & 120 & 60 & 337,5 & 12,1 & 7060 & 1284 & 81,82 \\
\hline 26 & 7,5 & 60 & 40 & 175 & 11,8 & 7060 & 1979 & 71,97 \\
\hline 27 & 7,5 & 180 & 80 & 500 & 11,9 & 6919 & 487 & 92,96 \\
\hline 28 & 4 & 60 & 80 & 500 & 11,9 & 6870 & 487 & 92,91 \\
\hline 29 & 7,5 & 60 & 80 & 175 & 11,6 & 7274 & 2782 & 61,76 \\
\hline 30 & 4 & 60 & 40 & 500 & 12,1 & 7114 & 1497 & 78,95 \\
\hline
\end{tabular}


(Adequate Precision) değeri de 21,901 olarak bulunmuştur ve 4' den büyük olması gerekmektedir [26] ve bulunan değer modelin uygun olduğunu göstermektedir. Uyum eksikliğinin (The lack of fit) olasılık değeri (Prob $>$ F- probability value) 0,0342 olarak bulunmuştur. Olasılık değerinin 0,0500'den küçük olması uyum eksikliğinin anlamlı olduğunu belirtmektedir. Yapılan çalışmada korelasyon katsayısı değeri ise $\left(\mathrm{R}^{2}=0,9578\right)$ 0,80'den yüksek olarak elde edilmiştir ve toplam farklılığın yalnızca \%4,22'lik kısmının model ile açıklanamayabileceği anlamına gelmektedir. Joglekar ve May' e göre uyumlu bir model için $\mathrm{R}^{2}$ değeri en az 0,80 olmalıdır [27]. Yüksek $\mathrm{R}^{2}$ değeri tasarım alanında, elde edilen ve hesaplanan sonuçlar arasında iyi bir uyum olduğunu sergilemektedir. $\mathrm{Bu}$ çalışmada $\mathrm{B}, \mathrm{D}, \mathrm{C}^{2}, \mathrm{D}^{2}, \mathrm{AC}$, $\mathrm{CD}$ model terimleri anlamlı bulunmuştur ve yanıtın küpü alınarak quadratik model oluşturulmuştur. Bunun nedeni farklı çalışma koşullarından elde edilen \% Bor giderimi yanıtlarının maksimum ve minimum (94,7 ile 1,89) değerlerinin oranının 50,1058 gibi bir sayı vermesidir. Oranın 10' dan büyük olması yanıtın bir dönüşüme ihtiyacı olduğunu göstermektedir.

Elde edilmiş olan quadratik modelin kodlanmış değerlerle ifade edilmiş olduğu eşitlik aşağıda verilmiştir (Eş. 2).

$(\% \mathrm{~B} \text { Giderimi })^{3}=+5,647 \mathrm{E}+005-10057,66 *$

$\mathrm{A}+45751,36 * \mathrm{~B}+21261,14 * \mathrm{C}+1,513 \mathrm{E}+005 *$

$\mathrm{D}-12590,37 * \mathrm{~A}^{2}+15564,77 * \mathrm{~B}^{2}+49483,94$

* $\mathrm{C}^{2}-61878,41 * \mathrm{D}^{2}+20437,65 *$

$\mathrm{A} * \mathrm{~B}-59218,05 * \mathrm{~A} * \mathrm{C}+28105,52 *$

A*D-1872,87*B*C-5724,09*B*D+66038,87*C*D
Elde edilmiş olan quadratik modelin gerçek değerlerle ifade edilmiş olduğu eşitlik aşağıda verilmiştir (Eş. 3).

$(\% \text { B Giderimi })^{3}=+2,91811 \mathrm{E}+005+86334,24145 *$ Başlangıç pH-602,54838*Tepkime Süresi-9724,03962*Tepkime

Sicaklığ $1+795,90726 * \mathrm{CaOH}_{2} / \mathrm{B}_{2} \mathrm{O}_{3}-4111,14165 *$ Başlangıç $\mathrm{pH}^{2}+4,32355^{*}$ Tepkime Süresi ${ }^{2}+123,70984 *$ Tepkime S1caklığ $12-2,34332 * \mathrm{CaOH}_{2} / \mathrm{B}_{2} \mathrm{O}_{3}{ }^{2}+194,64428 * \mathrm{pH} *$ Tepkime Süresi-1691,94432 * Başlangıç pH *

Tepkime Sicaklığ $1+98,83259 * \mathrm{pH} * \mathrm{CaOH}_{2} / \mathrm{B}_{2} \mathrm{O}_{3}-9,89406$

* Tepkime Süresi * Tepkime Sicaklığ $-0,58709$ *

Tepkime Süresi $* \mathrm{CaOH}_{2} / \mathrm{B}_{2} \mathrm{O}_{3}+20,31965 *$

Tepkime S1caklığg $1 * \mathrm{CaOH}_{2} / \mathrm{B}_{2} \mathrm{O}_{3}$

Seçilen modelin gerçek duruma uygun olup olmadığı önemli bir şeydir. Modelin uygun olup olmadığ 1 ise "Design Expert" yazılımından (v6.06, Stat-Ease Inc., Minneapolis, MN, USA) elde edilen studentleştirilmiş artıkların normal olasılık grafiği ile gerçek ve tahmin edilen değerlerin karşılaştırıldığ diagnostik grafiklerin incelenmesiyle anlaşılabilir [28]. Şekil 3a (\%B Giderimi) ${ }^{3}$ için studentleştirilmiş artıkların normal olasılık grafiğini göstermektedir. Normal olasılık grafiği artıkların normal bir dağılım izleyip izlemediğini gösterir eğer artıklar normal bir dağılım izliyorlarsa noktalar düz bir çizgi izler ve uygun olduğu anlamına gelir [28]. Bu çalışmada da ufak sapmalar haricinde Şekil 3a' deki noktaların düz bir çizgi izlediği ve uygunluğunun kabul edilebilir olduğu görülmektedir. Şekil 3b' de de gerçek ve tahmin edilen değerlerin karşılaştırıldığı grafik yer almaktadır. Bu grafiktede noktaların düz bir çizgi izlediği ve uygunluğunun kabul edilebilir olduğu görülmektedir.

Tablo 4. Önerilen quadratik modelin varyans analizi (ANOVA) tablosu (Analysis of variance (ANOVA) of proposed quadratic model)

\begin{tabular}{lllllll}
\hline Kaynak & $\begin{array}{l}\text { Kareler } \\
\text { Ortalamas1 }\end{array}$ & $\begin{array}{l}\text { Serbestlik } \\
\text { Derecesi }\end{array}$ & $\begin{array}{l}\text { Ortalama } \\
\text { Kareler }\end{array}$ & F Değeri & $\begin{array}{l}\text { Prob }>\text { F } \\
\text { Değeri }\end{array}$ & \\
\hline Model & $9,74447 \mathrm{E}+11$ & 14 & 69603357054 & 24,33418 & $<0,0001$ & Anlamlı \\
A & 2427758089 & 1 & 2427758089 & 0,848774 & 0,3715 & \\
B & 50236487051 & 1 & 50236487051 & 17,56329 & 0,0008 & \\
C & 10848862643 & 1 & 10848862643 & 3,792894 & 0,0704 & \\
D & $5,49522 \mathrm{E}+11$ & 1 & $5,49522 \mathrm{E}+11$ & 192,1195 & $<0,0001$ & \\
A2 & 4347907197 & 1 & 4347907197 & 1,520081 & 0,2366 & \\
B2 & 6644902953 & 1 & 6644902953 & 2,323139 & 0,1483 & \\
C2 & 67163242757 & 1 & 67163242757 & 23,48109 & 0,0002 & \\
D2 & $1,05022 \mathrm{E}+11$ & 1 & $1,05022 \mathrm{E}+11$ & 36,71706 & $<0,0001$ & \\
AB & 6683160005 & 1 & 6683160005 & 2,336514 & 0,1472 & \\
AC & 56108441379 & 1 & 56108441379 & 19,61619 & 0,0005 & \\
AD & 12638720801 & 1 & 12638720801 & 4,41865 & 0,0529 & \\
BC & 2255440453 & 1 & 2255440453 & 0,788529 & 0,3886 & \\
BD & 524242641,6 & 1 & 524242641,6 & 0,183282 & 0,6747 & \\
CD & 69778115137 & 1 & 69778115137 & 24,39528 & 0,0002 & \\
Art1k & 42904687976 & 15 & 2860312532 & & & \\
Uyum & 39447129168 & 10 & 3944712917 & 5,704477 & 0,0342 & Anlaml1 \\
Eksikliği & 3457558808 & 5 & 691511761,6 & & & \\
Hata & $1,01735 \mathrm{E}+12$ & 29 & & & & \\
TOPLAM & Standart Sapma= $53481,89, \mathrm{PRESS}=2,322 \mathrm{E}+011, \mathrm{R}^{2}=0,9578, \mathrm{R}_{\mathrm{adj}}{ }^{2}=0,9185$, Uygun Kesinlik=21,901 &
\end{tabular}




\subsection{X-Işını Kırınımı (XRD) Analizi \\ (X-Ray Diffraction (XRD) Analysis)}

Tepkime sonucu oluşan katı numune kobalt (CoKa) 1şınımı kullanılarak X-ışını kırınımı (XRD) cihazında kalitatif olarak analiz edilmiştir. Oluşan katı numunenin kristal bir yapıya sahip olduğu görülmüştür. Şekil 4'de başlangıç pH değeri 5,75, tepkime sicaklığ $120^{\circ} \mathrm{C}$, tepkime süresi $120 \mathrm{~min}$ ve $\% \mathrm{Ca}(\mathrm{OH})_{2} / \mathrm{B}_{2} \mathrm{O}_{3}$ oranı 337,50 olan deney koşullarında elde edilmiş katı numunenin XRD diyagramında, tepkime sonucu oluşmuş $\mathrm{Ca}_{2} \mathrm{~B}_{2} \mathrm{O}_{5} \bullet\left(\mathrm{H}_{2} \mathrm{O}\right)$ (Parasibirskite) ve tepkimeye girmemiş olan $\mathrm{Ca}(\mathrm{OH})_{2}$ (Portlantit) pikleri görülmektedir. $\mathrm{Ca}_{2} \mathrm{~B}_{2} \mathrm{O}_{5} \bullet\left(\mathrm{H}_{2} \mathrm{O}\right)$, çözeltideki $\mathrm{Ca}(\mathrm{OH})_{2}$ ve borat anyonu arasındaki tepkime ile oluşmuştur. Gerçekleşmiş olan tepkime aşağıda verilmiştir (R1).

$2 \mathrm{Ca}^{+2}(a q)+2 \mathrm{~B}(\mathrm{OH})_{4}^{-}(a q)+2 \mathrm{OH}^{-}(a q) \rightarrow$

$\mathrm{Ca}_{2} \mathrm{~B}_{2} \mathrm{O}_{5} \cdot\left(\mathrm{H}_{2} \mathrm{O}\right)_{(s)}+4 \mathrm{H}_{2} \mathrm{O}_{(l)}$

\subsection{Bor Giderimi Üzerine Deney Parametrelerinin Etkisi} (Effect of Experimental Parameters on Boron Removal)

\subsubsection{Başlangıç pH'ın etkisi (Effect of initial $p H$ )}

Başlangıç pH'ının etkisinin incelenmesinin nedeni tepkime pH'ını farklı değerlerde tutup bu farklı değerlerde oluşacak olan bor bileşikleriyle $\mathrm{Ca}(\mathrm{OH})_{2}$ tepkimelerinin giderim verimi üzerindeki etkisinin incelenmektir. Yapılan deneylerde başlangıç pH'ının sınır koşulları kodlanmış değerler olarak -1 ve +1 için sırasıyla 4 ve 7,5 seçilmiștir ve yanıt yüzey yöntemi (RSM) merkezi bileşik tasarımı (CCD) -2 ve +2 kodlanmış değerleri için 2,25 ve $9,25^{\prime}$ de birer deney önermiștir. Anova tablosu (Tablo 4) incelendiğinde başlangıç $\mathrm{pH}$ değerinin bor giderimi üzerine anlamlı bir etkisinin olmadığ 1 görülmüştür. Aynı zamanda kullanılan program tarafindan olușturulmuș olan Şekil 5'deki grafikler incelendiğinde de yine aynı sonuç görülmektedir. Başlangıç pH'ının etkili olmamasının nedeninin başlangıç $\mathrm{pH}$

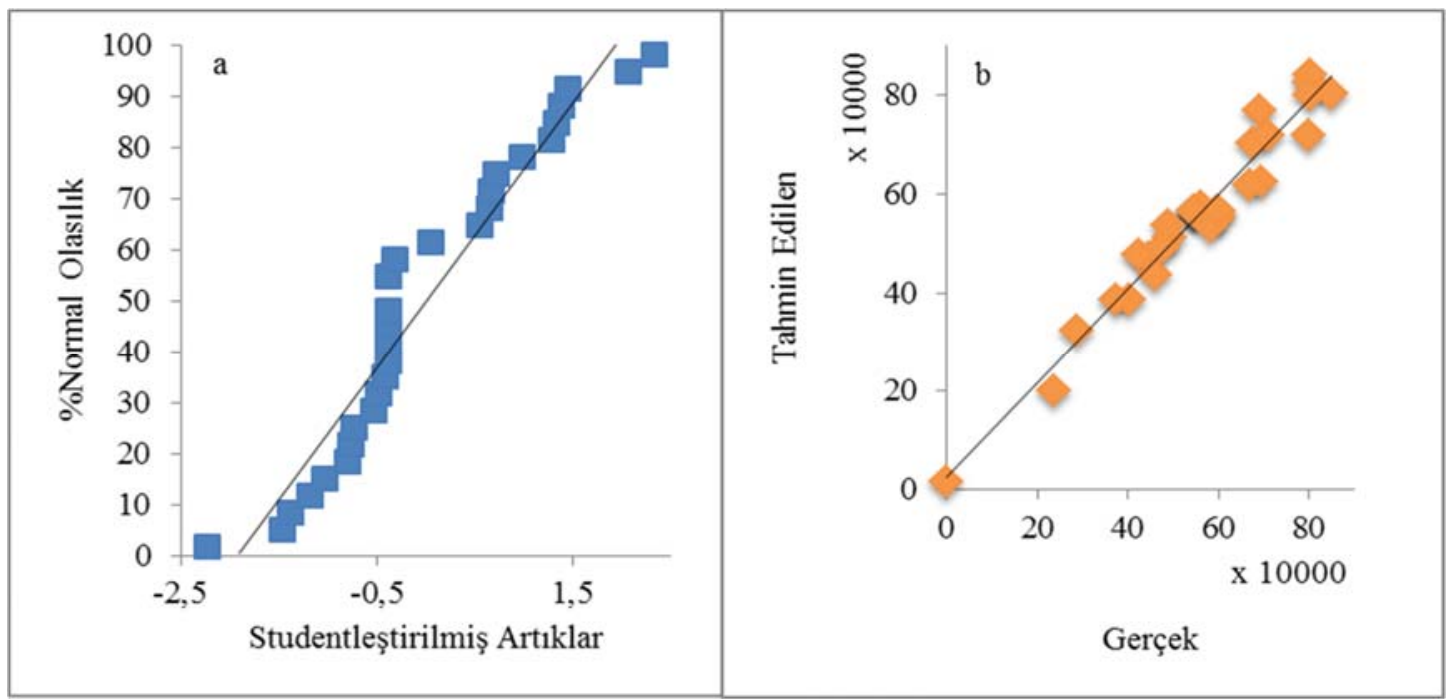

Şekil 3. a) (\%B Giderimi $)^{3}$ için studentleştirilmiş artıkların normal olasılık grafiği b) Gerçek değerlere karşı tahmin edilen değerlerin grafiği ( a) Normal probability plot of studentized residuals for (B removal\%) ${ }^{3}$ b) Graph of estimated value versus the actual value)

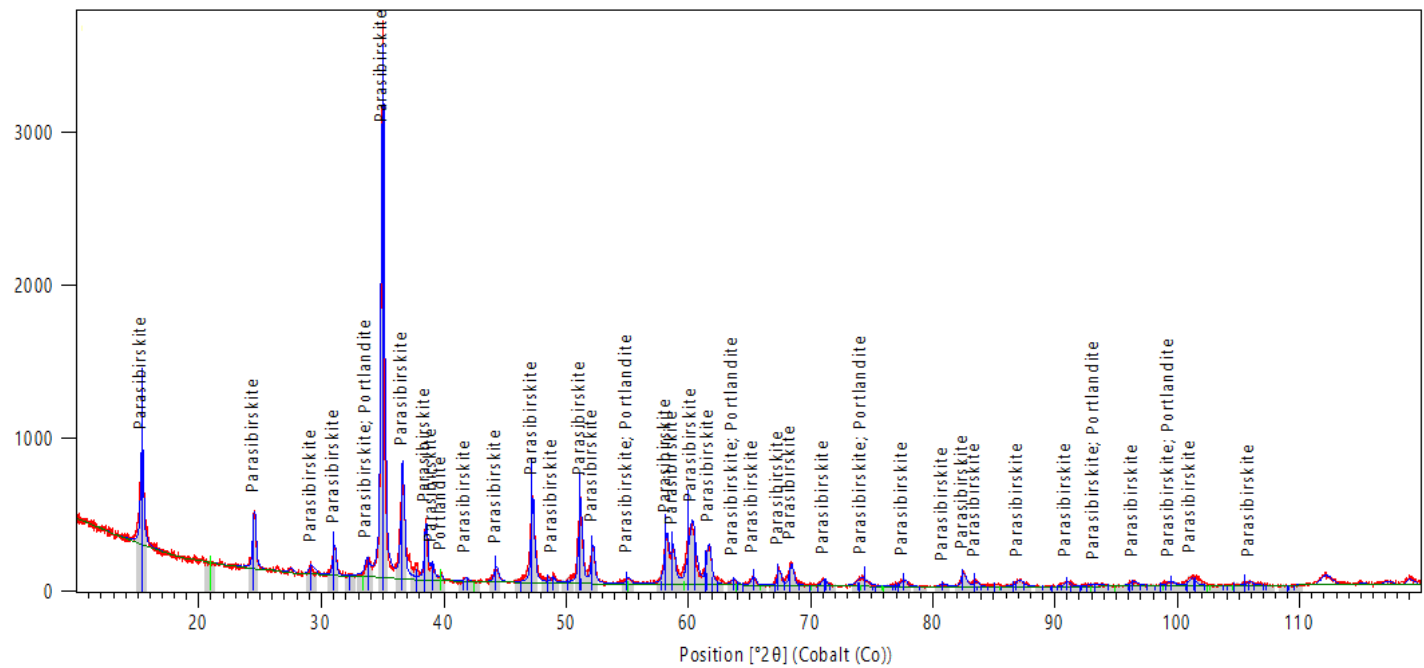

Şekil 4. Oluşan katının X-1şını kırınımı diyagramı (X-ray diffraction diagram of formed solid) 
ayarlanmasının ardından atık suya ilave edilen $\mathrm{Ca}(\mathrm{OH})_{2}$ ile beraber son pH'ın 11,3-12,3 aralığına yükselmesi ve bu pH aralığında atık suda bulunan borun çok büyük bir kısmının Şekil 6'daki grafikte de görüleceği gibi monoborat $\left(\mathrm{B}(\mathrm{OH})_{4}^{-}\right.$ ) yapısında bulunması; böylelikle de farklı başlangıç $\mathrm{pH}$ değerlerine sahip olmasına rağmen bütün tepkimelerin yalnızca (R1) tepkimesinde gösterilen mekanizma ile gerçekleşmesi olduğu düşünülmektedir.

\subsubsection{Tepkime süresinin etkisi (Effect of reaction time)}

Bir diğer parametre olarak tepkime süresi seçilmiş ve sınır koşulları kodlanmış değerler olarak -1 ve +1 için sırasıyla 60 ve 180 min seçilmiştir ve yanıt yüzey yöntemi (RSM) merkezi bileşik tasarımı (CCD) -2 ve +2 kodlanmış değerleri 0 ve 240 min için de birer deney önermiştir. Hem Anova tablosu (Tablo 4) hem de kullanılan program tarafindan oluşturulmuş olan Şekil 7'deki grafikler incelendiğinde sürenin bor giderimi üzerine anlamlı bir etkisinin olduğu görülmüştür. Bunun nedeninin süre artışılla beraber
$\mathrm{Ca}(\mathrm{OH})_{2}$ ile reaksiyona giren $\mathrm{B}(\mathrm{OH})_{4}{ }^{-}$miktarının artmas1 ve $\mathrm{Ca}(\mathrm{OH})_{2}$ tarafindan adsorblanan bor miktarının artması olduğu düşünülmektedir. Yılmaz vd. [8] yapmış oldukları çalışmada sürenin etkisini, tepkime süresince belirli aralıklarla aldıkları numunelerde $\mathrm{B}_{2} \mathrm{O}_{3}$ analizi yaparak incelemişler ve süre artışı ile bor gideriminin arttığını gözlemlemişlerdir. Aynı zamanda Itakura vd. [15] hidrotermal minerilazyon yöntemi ile atık sudan bor giderimi deneylerinde süre artışı ile bor gideriminin arttığını tespit etmişlerdir.

\subsubsection{Tepkime sicaklı̆̆ının etkisi (Effect of reaction temperature)}

Tepkime sıcaklığı sınır koşul aralıkları ise 40 ve $80^{\circ} \mathrm{C}$ arası seçilmiş ve $-2 \mathrm{ve}+2$ kodlanmış değerleri olan 20 ve $100^{\circ} \mathrm{C}$ ' da iki deney yapılmıştır. İstatiksel çalışmaların ardından da tepkime sicaklığında anlamlı bir etkisinin olmadığ1 görülmüştür (Tablo 4, Şekil 8). Tepkime sıcaklığının etkisini daha iyi anlayabilmek için öncelikle gerçekleşen (R1) tepkimesinin ekzotermik mi yoksa endotermik mi olduğunun
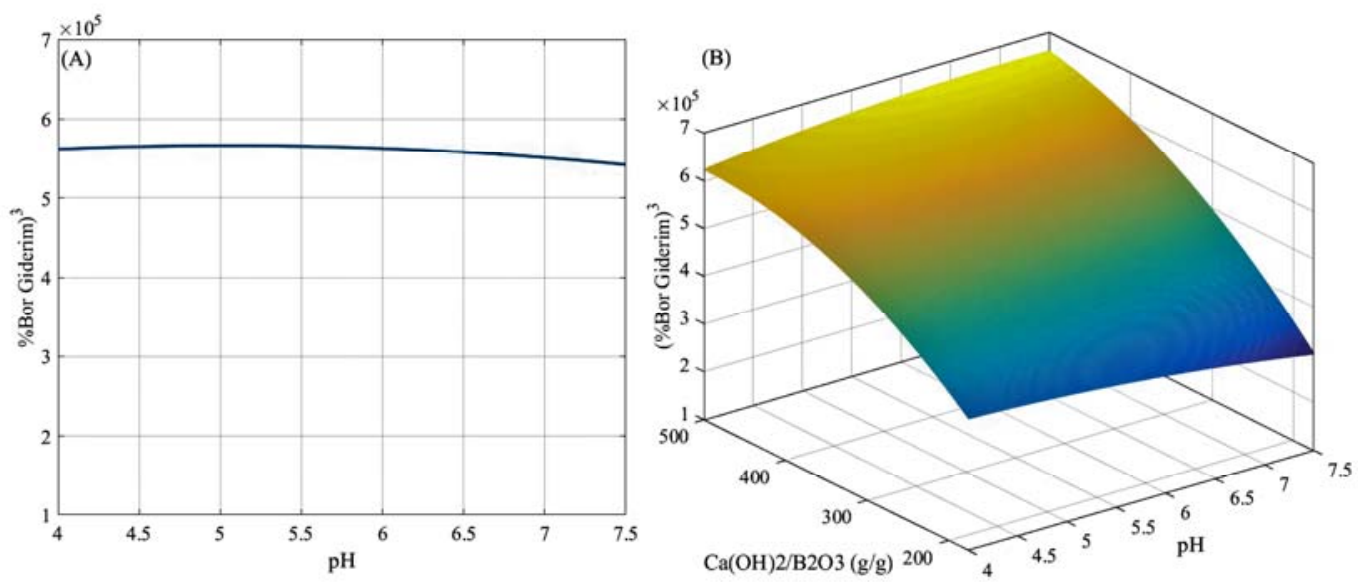

Şekil 5. a) Başlangıç pH'ına karşı \%B giderimi ${ }^{3}$ tepkime süresi: 120 min tepkime sıcaklı̆̆ı: $60^{\circ} \mathrm{C} \% \mathrm{Ca}(\mathrm{OH}) 2 / \mathrm{B} 2 \mathrm{O} 3$ oranı: 337,50 b) Başlangıç pH'1 ve $\% \mathrm{Ca}(\mathrm{OH})_{2} / \mathrm{B}_{2} \mathrm{O}_{3}$ oranına göre cevap yüzey tepkime süresi: 120 min, tepkime sicaklığı: $60^{\circ} \mathrm{C}$ (a) $\mathrm{B}$ removal $\%^{3}$ versus initial $\mathrm{pH}$ reaction time: 120 min reaction temperature: $60^{\circ} \mathrm{C} \mathrm{Ca}(\mathrm{OH})_{2} / \mathrm{B}_{2} \mathrm{O}_{3}$ ratio $\left.\%: 337,50 \mathrm{~b}\right)$ According to initial $\mathrm{pH}$ and $\mathrm{Ca}$ $(\mathrm{OH})_{2} / \mathrm{B}_{2} \mathrm{O}_{3}$ ratio\% response surface reaction time: 120 min reaction temperature: $60^{\circ} \mathrm{C}$ )

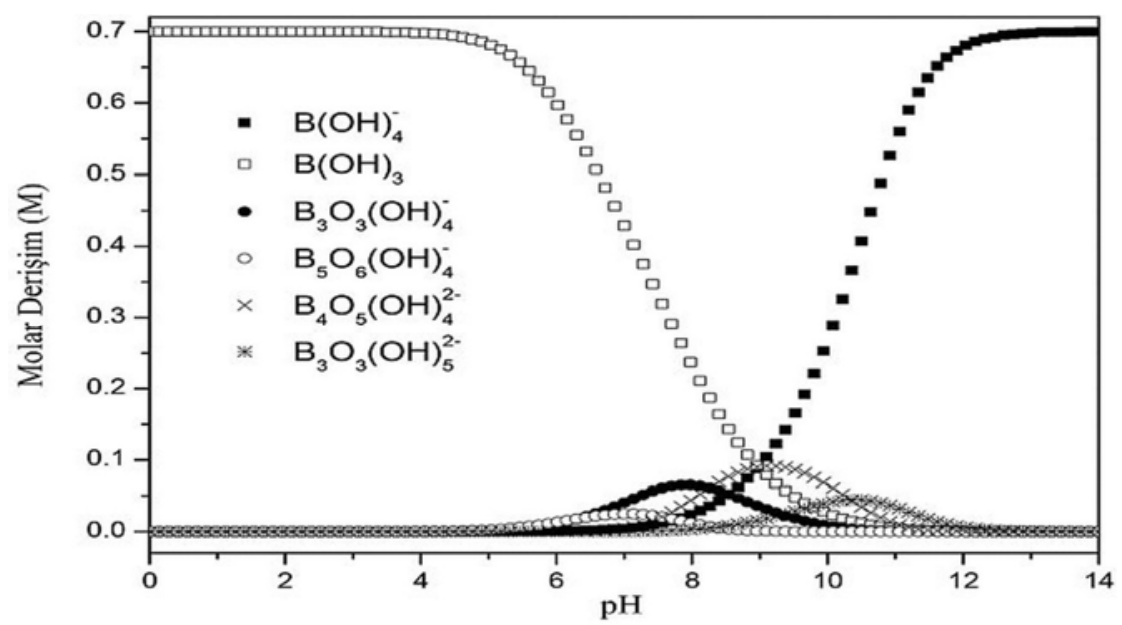

Şekil 6. pH' a bağlı olarak bor bileşiklerinin sudaki dağılımı (Distribution of the boron compound as a function of pH) [29] 

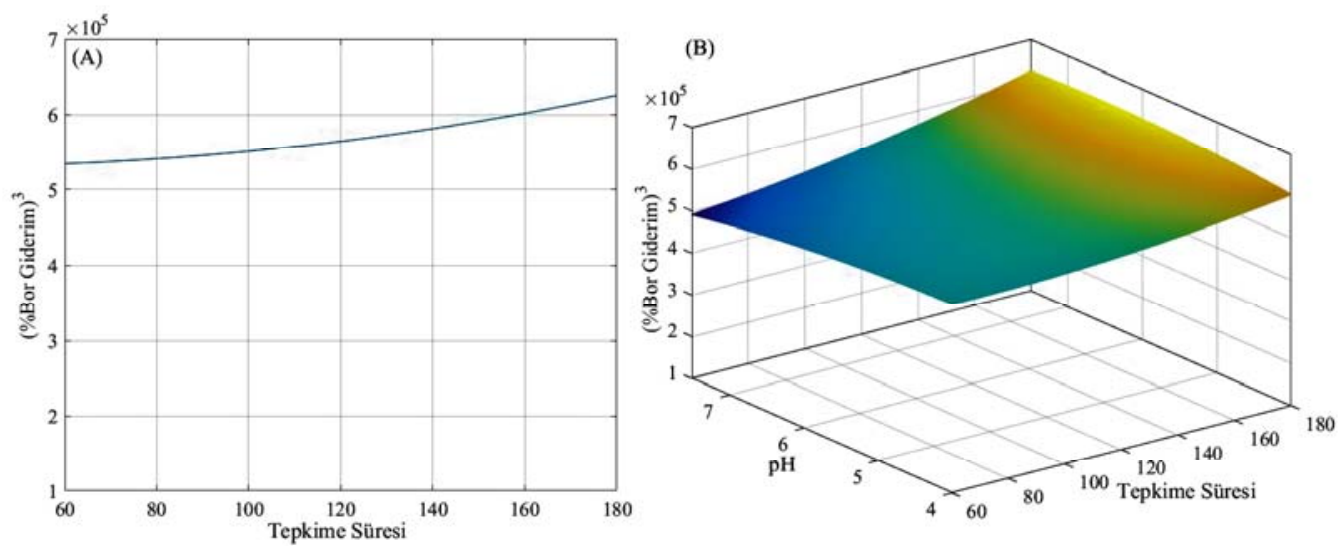

Şekil 7. a) Tepkime süresi'ne karşı $\% \mathrm{~B}$ giderimi ${ }^{3}$ başlangıç $\mathrm{pH}^{\prime} 1$ : 5,75 tepkime sıcaklı̆̆ 1 : $60^{\circ} \mathrm{C} \% \mathrm{Ca}(\mathrm{OH}) 2 / \mathrm{B} 2 \mathrm{O} 3$ oranı: $337,50 \mathrm{~b}$ ) tepkime süresi ve başlangıç $\mathrm{pH}$ 'ına göre cevap yüzey tepkime sıcaklığı: $60^{\circ} \mathrm{C} \% \mathrm{Ca}(\mathrm{OH}) 2 / \mathrm{B} 2 \mathrm{O} 3$ oranı: 337,50 (a) B removal $\%{ }^{3}$ versus reaction time initial $\mathrm{pH}$ : 5.75 reaction temperature: $60^{\circ} \mathrm{C} \mathrm{Ca}(\mathrm{OH})_{2} / \mathrm{B}_{2} \mathrm{O}_{3}$ ratio\%: $337.50 \mathrm{~b}$ ) According to reaction time and initial $\mathrm{pH}$ response surface reaction temperature: $60^{\circ} \mathrm{C} \mathrm{Ca}(\mathrm{OH})_{2} / \mathrm{B}_{2} \mathrm{O}_{3}$ ratio\%: 337.50)
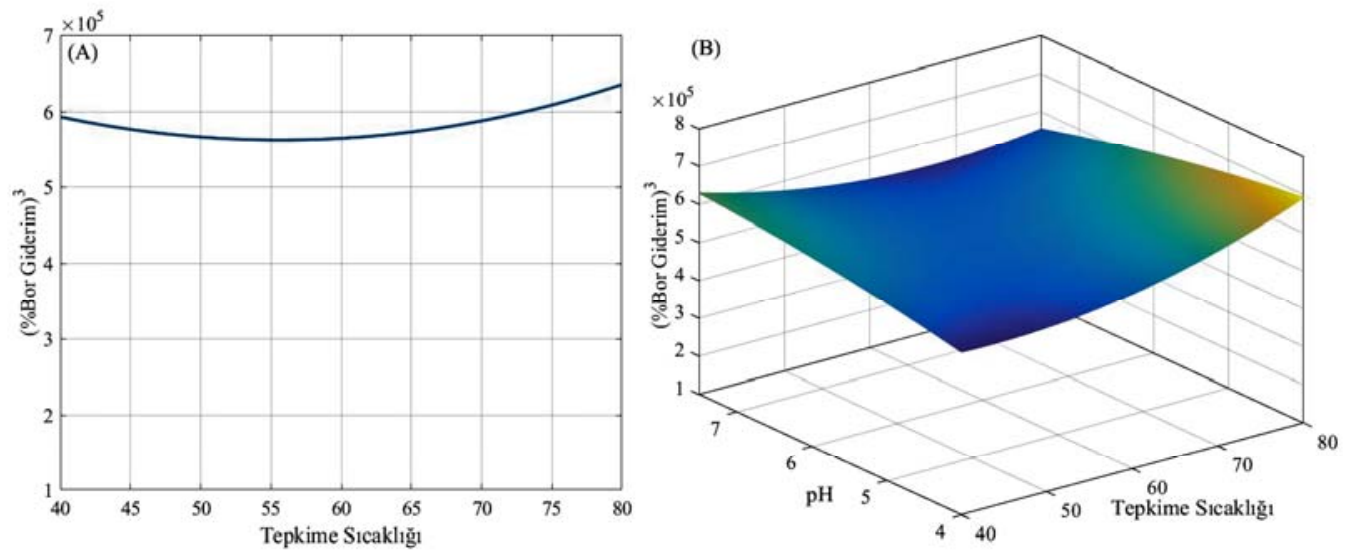

Şekil 8. a) Tepkime sıcaklığına karşı $\% \mathrm{~B}$ giderimi ${ }^{3}$ başlangıç pH'ı: 5,75 tepkime süresi: 120 min $\% \mathrm{Ca}(\mathrm{OH})_{2} / \mathrm{B}_{2} \mathrm{O}_{3}$ oranı: $337,50 \mathrm{~b}$ ) Tepkime Sıcaklığı ve başlangıç $\mathrm{pH}$ 'ına göre cevap yüzey tepkime süresi: $120 \mathrm{~min} \% \mathrm{Ca}(\mathrm{OH})_{2} / \mathrm{B}_{2} \mathrm{O}_{3}$ oranı: 337,50 (a) B removal $\%{ }^{3}$ versus reaction temperature $\mathrm{pH}: 5.75$ reaction time: $120 \operatorname{min~} \mathrm{Ca}(\mathrm{OH})_{2} / \mathrm{B}_{2} \mathrm{O}_{3}$ ratio\%: 337.50 b) According to reaction temperature and $\mathrm{pH}$ response surface reaction time: $120 \mathrm{~min} \mathrm{Ca}(\mathrm{OH})_{2} / \mathrm{B}_{2} \mathrm{O}_{3}$ ratio $\%: 337.50$ )

ortaya konulması gerekmektedir. (R1) tepkimesine ait $298 \mathrm{~K}$ sıcaklıktaki $\Delta \mathrm{H}$ hesabı aşağıda yapılmıştır (Eş. 4).

Tablo 5. Tepkime girdi ve ürünlerinin 298 K'deki entalpileri

(Enthalpies of reactants and products at $298 \mathrm{~K})[30,31]$

\begin{tabular}{ll}
\hline & $\Delta \mathrm{H}_{298}(\mathrm{~kJ} / \mathrm{mol})$ \\
\hline $\mathrm{Ca}^{+2}(a q)$ & $-542,83$ \\
$\mathrm{~B}(\mathrm{OH})_{4^{-}}(a q)$ & $-1344,03$ \\
$\mathrm{OH}_{(a q)}^{-}$ & $-229,99$ \\
$\mathrm{Ca}_{2} \mathrm{~B}_{2} \mathrm{O}_{5} \cdot\left(\mathrm{H}_{2} \mathrm{O}\right)_{(s)}$ & $-3041,80$ \\
$\mathrm{H}_{2} \mathrm{O}$ & $-242,00$ \\
\hline
\end{tabular}

$$
\begin{aligned}
& (\Delta \mathrm{H})_{298}=\left[1 * \Delta \mathrm{H}_{\mathrm{Ca} 2 \mathrm{~B} 2 \mathrm{O} 5 \cdot(\mathrm{H} 2 \mathrm{O})(s)}+4 * \Delta \mathrm{H}_{\mathrm{H} 2 \mathrm{O}}\right]- \\
& {\left[2 * \Delta \mathrm{H}_{\mathrm{Ca}+2(a q)}+2 * \Delta \mathrm{H}_{\mathrm{B}(\mathrm{OH}) 4-(a q)}+2 * \Delta \mathrm{H}_{\mathrm{OH}-(a q)}\right]} \\
& (\Delta \mathrm{H})_{298}=[1 *-3041,80+4 *-242,00]- \\
& {[2 *-542,83+2 *-1344,03+2 *-229,99]=223,90 \mathrm{~kJ} / \mathrm{mol}}
\end{aligned}
$$

223,90 kJ/mol olarak bulunan $(\Delta \mathrm{H})_{298}$ değeri tepkimenin endotermik olduğunu ve sıcaklık artışı ile tepkimenin ürünler yönüne kayacağını göstermektedir. Ancak bor giderimi üzeinde etkin olan iki temel mekanizmadan biri kimyasal tepkime ile $\mathrm{Ca}_{2} \mathrm{~B}_{2} \mathrm{O}_{5} \bullet\left(\mathrm{H}_{2} \mathrm{O}\right)$ oluşumu iken diğer mekanizma $\mathrm{Ca}(\mathrm{OH})_{2}$ 'in bor iyonlarını fiziksel olarak adsorblama mekanizmasıdır ve bu fiziksel adsorblama mekanizması sıcaklık ile azalmaktadır. Tepkime sıcaklığının artışı ile bor giderim veriminin artmayışının nedeninin (R1) tepkimesi ile $\mathrm{Ca}_{2} \mathrm{~B}_{2} \mathrm{O}_{5} \bullet\left(\mathrm{H}_{2} \mathrm{O}\right)$ oluşumu artarken fiziksel adsorblanmanın azalması olduğu düşünülmektedir. 

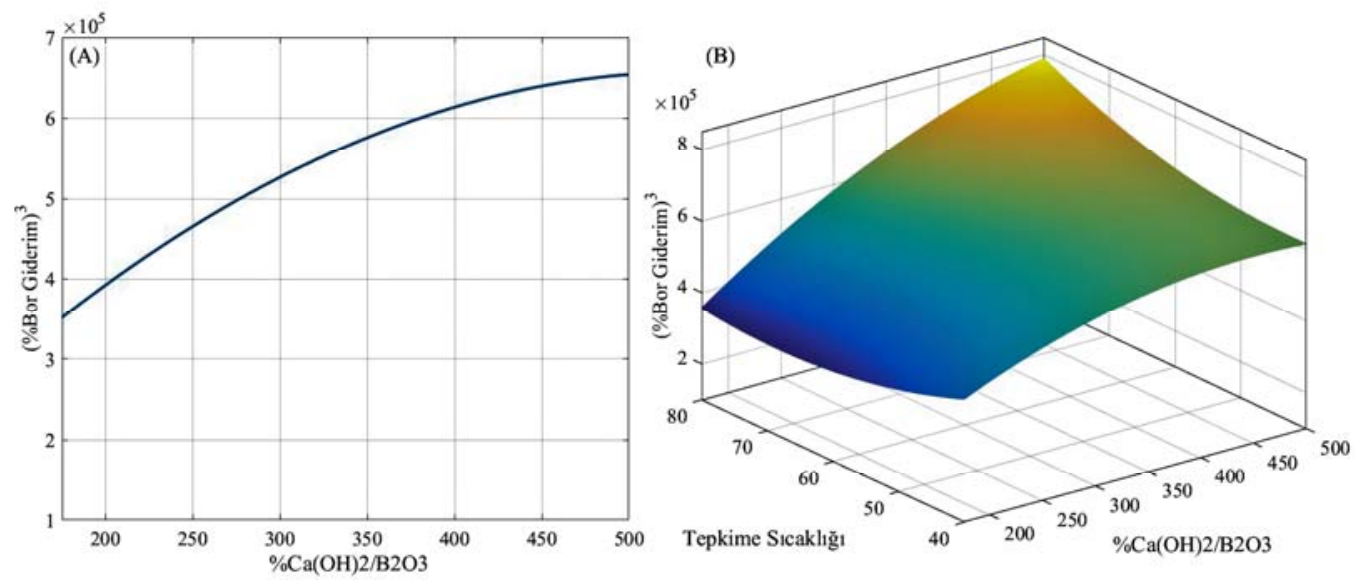

Şekil 9. a) $\% \mathrm{Ca}(\mathrm{OH})_{2} / \mathrm{B}_{2} \mathrm{O}_{3}$ oranına karşı $\% \mathrm{~B}$ giderimi ${ }^{3}$ başlangıç $\mathrm{pH}$ '1: 5,75 tepkime süresi: 120 min tepkime sıcaklı̆̆ı: $60^{\circ} \mathrm{C}$ b) $\% \mathrm{Ca}(\mathrm{OH})_{2} / \mathrm{B}_{2} \mathrm{O}_{3}$ oranı ve tepkime sıcaklığına göre cevap yüzey başlangıç $\mathrm{pH}$ '1: 5,75, tepkime süresi: 120 min (a) $\mathrm{B}$ removal $\%{ }^{3}$ versus $\mathrm{Ca}(\mathrm{OH})_{2} / \mathrm{B}_{2} \mathrm{O}_{3}$ ratio\% $\mathrm{pH}$ : 5.75 reaction time: 120 min reaction temperature: $60^{\circ} \mathrm{C}$ b) According to $\mathrm{Ca}(\mathrm{OH})_{2} / \mathrm{B}_{2} \mathrm{O}_{3}$ ratio $\%$ and reaction temperature response surface $\mathrm{pH}: 5.75$ reaction time: $120 \mathrm{~min}$ )

Tablo 6. Optimum çalışma koşulları (Optimum operating conditions)

\begin{tabular}{lllll}
\hline $\begin{array}{l}\mathrm{pH}- \\
(\mathrm{A})\end{array}$ & $\begin{array}{l}\text { Süre min } \\
(\mathrm{B})\end{array}$ & $\begin{array}{l}\mathrm{S}_{1} \text { cakl1k } \\
(\mathrm{C})\end{array}$ & $\begin{array}{l}\% \mathrm{Ca}(\mathrm{OH})_{2} / \mathrm{B}_{2} \mathrm{O}_{3} \\
\%(\mathrm{~g} / \mathrm{g})(\mathrm{D})\end{array}$ & $\begin{array}{l}\% \mathrm{~B} \text { Giderimi } \\
(\text { Yanit })\end{array}$ \\
\hline 5,74 & 179,96 & 76,46 & 499,90 & 93 \\
6,02 & 173,43 & 77,60 & 498,79 & 93 \\
6,46 & 179,01 & 77,64 & 497,27 & 93 \\
5,73 & 179,25 & 77,87 & 482,08 & 93 \\
6,37 & 179,21 & 77,49 & 497,93 & 93 \\
5,86 & 179,33 & 77,26 & 499,97 & 93 \\
\hline
\end{tabular}

\subsection{4. $\% \mathrm{Ca}(\mathrm{OH})_{2} / \mathrm{B}_{2} \mathrm{O}_{3}$ oraninin etkisi (Effect of $\mathrm{Ca}(\mathrm{OH})_{2} / \mathrm{B}_{2} \mathrm{O}_{3} \%$ ratio)}

$\% \mathrm{Ca}(\mathrm{OH})_{2} / \mathrm{B}_{2} \mathrm{O}_{3}$ oranının bor giderimi üzerine etkisi incelenirken sınır koşulları 175-500 olarak belirlenmiş ve 12,50 ve 662,50 değerlerinde de iki deney yapılmış ve giderim üzerine anlamlı bir etkisinin olduğu ve $\mathrm{Ca}(\mathrm{OH})_{2}$ miktarının artmasıyla bor giderim veriminin arttı̆ 1 görülmüştür (Tablo 4, Şekil 9). Atık suya ilave edilen $\mathrm{Ca}(\mathrm{OH})_{2}$ miktarının artmasıyla beraber bor giderimi üzerindeki iki temel mekanizma olan $\mathrm{Ca}_{2} \mathrm{~B}_{2} \mathrm{O}_{5} \bullet\left(\mathrm{H}_{2} \mathrm{O}\right)$ oluşumu ve fiziksel adsorbsiyon mekanizmalarının Le Chatelier ilkesine göre ürün yönüne doğru kayıp atık sudaki bor miktarını azalttığı düşünülmektedir.

\subsection{Parametrelerin Optimizasyonu (Optimization of Parameters)}

Yapılan deneysel çalışmanın temel amacı bir bor fabrikası atık suyundan borun giderilip derin deniz deşarj limitlerine uygun suyun üretilmesi olmasından dolayı giderim sonrası bor miktarının $500 \mathrm{mg} / \mathrm{L}$ 'in altında olması gerekmektedir. Bundan dolayı yaklaşı $7000 \mathrm{mg} / \mathrm{L}$ bor içeren giriş atık suyunun en az \%93'lük verime sahip bir arıtım prosesinden geçmesi amaçlanan yanıt değeri olarak karşımıza çıkmaktadır. Bu yanıt değerini maliyet açısından optimum 276 koşulları elde etmek maksadıyla design expert programı aracılığıyla ilk önce $\mathrm{pH}$, tepkime süresi, tepkime sıcakığı, $\% \mathrm{Ca}(\mathrm{OH})_{2} / \mathrm{B}_{2} \mathrm{O}_{3}$ oranı parametreleri çalışma aralığında; yanıt değer olan $\% \mathrm{~B}$ giderimi ise minimum \%93 olarak seçilmiştir. Seçimin ardından program arzu edilebilirlik (desirability) değeri 1 olan 624 farklı çözüm önermiştir. Bu çözümlerin arasından maliyet kıstasları çerçevesinde seçimler yapılmıştır. Çalışmanın endüstriyel uygulama safhasında en büyük maliyet kaleminin enerji olacağ1 öngörülerek en soğuk sıcaklık değerleri seçilmiştir ardından bir diğer önemli maliyet kalemi olan başlangıç pH'ının en yüksek değerlerde seçilmiştir. $\% \mathrm{Ca}(\mathrm{OH})_{2} / \mathrm{B}_{2} \mathrm{O}_{3}$ ve tepkime süresine dair ise bir kıstas konulmamıştır. Sonuçlar Tablo 6 'da yer almaktadır.

\section{SONUÇLAR (CONCLUSIONS)}

$\mathrm{Bu}$ çalışmada, Bandırma Bor ve Asit Fabrikaları İşletme Müdürlüğü atık suyundan kalsiyum hidroksit $\mathrm{Ca}(\mathrm{OH})_{2}$ kullanılarak kimyasal çöktürme ile borun uzaklaştırılması çalışılmış ve yanıt yüzey yöntemi (RSM) kullanılarak optimizasyonu yapılmıştır. Atık su kimyasal arıtım prosesinde bor giderimi üzerine başlangıç $\mathrm{pH}$ 'ı, tepkime süresi, tepkime sicaklığ1 ve $\% \mathrm{Ca}(\mathrm{OH})_{2} / \mathrm{B}_{2} \mathrm{O}_{3}$ oran1 parametrelerinin etkileri yanıt yüzey yöntemi (RSM) 
merkezi bileşik tasarımı (CCD) kullanılarak incelenmiş ve optimizsayonu yapılmıştır. 0,9578 olarak bulunan regresyon katsayısı $\left(\mathrm{R}^{2}\right)$ tahmin edilen giderim ile gerçek giderimin birbirleriyle iyi bir uyum içinde olduğunu göstermiştir.

Yapılan 30 deneyin dördünde yaklaşık $7000 \mathrm{mg} / \mathrm{L}$ bor derişimine sahip atık suyun bor derişimi Türk çevre mevzuatına göre $500 \mathrm{mg} / \mathrm{L}$ olan bor sınır değerini altına başarıyla indirilmiştir. Düşük kurulum ve işletme maliyetlerinden dolayı kimyasal çöktürme ile atık sulardan bor gideriminin uygun bir yöntem olabileceği ortaya konulmuştur.

\section{TEŞEKKÜR (ACKNOWLEDGEMENT)}

Çalışmaya desteklerinden dolayı Eti Maden İşletmeleri Genel Müdürlüğü’ne derin teşekkürlerimizi sunarız.

\section{KAYNAKLAR (REFERENCES)}

1. Yılmaz O., Yalçınoğlu Y., Bilen M., Uludağ T., Şentürk B., Production of micronized calcined tincal from runof-mine tincal at pilot scale plant, Journal of the Faculty of Engineering and Architecture of Gazi University, 28 (3), 657-670, 2013.

2. Adair R., Boron, Rosen Publishing Group, New York, 2007.

3. Alıcılar A., Ökenek F., Kayran B., Tutak M., Flame retardation, smoke suppression and antibacterial efficiencies of boron additives in styrene acrylic paints, Journal of the Faculty of Engineering and Architecture of Gazi University, 30 (4), 701-709, 2015.

4. Gökdai D., Gürü M., Toğrul T., Synthesıs and characterization of elemental boron from boron oxide by mechanochemical method, Journal of the Faculty of Engineering and Architecture of Gazi University, 31 (2), 425-433, 2016.

5. WHO, Guidelines for Drinking-water Quality, 4th ed., World Health Organization, 2011.

6. Güler E., Kaya C., Kabay N., Arda M., Boron removal from seawater: state-of-the-art review, Desalination, 356, 85-93, 2015.

7. T.C Çevre ve Şehircilik Bakanlığı, Su Kirliliği Kontrolü Yönetmeliği, Dec.31, Resmi Gazete, 25687, 2004.

8. Yilmaz A.E., Boncukcuoğlu R., Bayar S., Fil B.A., Kocakerim, M.M., Boron removal by means of chemical precipitation with calcium hydroxide and calcium borate formation, Korean J. Chem. Eng, 29, 1382-1387, 2012.

9. Guan Z., Lv J., Bai P., Guo X., Boron removal from aqueous solutions by adsorption-A review, Desalination, 383, 29-37, 2016.

10. Darwish N.B., Kochkodan V., Hilal N., Boron removal from water with fractionized Amberlite IRA743 resin, Desalination, 370, 1-6, 2015.

11. Boubakri A., Bouguecha S.A.T., Dhaouadi I., Hafiane A., Effect of operating parameters on boron removal from seawater using membrane distillation process, Desalination, 373, 86-93, 2015.
12. Isa M.H., Ezechi E.H., Ahmed Z., Magram S.F., Kutty, S.R.M., Boron removal by electrocoagulation and recovery, Water Research, 51, 113-123, 2014.

13. Garcia-Segura S., Eiband M.M.S., de Melo J.V., Martínez-Huitle C.A., Electrocoagulation and advanced electrocoagulation processes: A general review about the fundamentals, emerging applications and its association with other technologies, Journal of Electroanalytical Chemistry, 801, 267-299, 2017.

14. Yazicigil Z., Oztekin Z., Boron removal by electrodialysis with anion-exchange membranes, Desalination, 190, 71-78, 2006.15. Itakura T., Sasai R., Itoh H., Precipitation recovery of boron from wastewater by hydrothermalmineralization, Water Research, 39, 2543-2548, 2005.

15. Garcia-Soto M.M.F., Camacho E.M., Boron removal by means of adsorption with magnesium oxide, Sep. Purif. Technol., 48, 36-44, 2006.

16. US Patent 3952085 , C.A. 1975, v.85, 67352.

17. Japanese Patent 3953572, C.A. 1981, v.84, 3125.

18. Geffen N., Semiat R., Eisen M.S., Balazs Y., Katz I., Dosoretz C.G., Boron removal from water by complexation to polyol compounds, J. Membr. Sci., 286, 45-51, 2006.

19. Isa M.H., Ezechi E.H., Ahmed Z., Magram S.F., Kutty, S.R.M., Boron removal by electrocoagulation and recovery, Water Res., 51, 113-123, 2014.

20. Ghafari S., Aziz H.A., Isa M.H., Zinatizadeh A.A., Application of response surface methodology (RSM) to optimize coagulation-flocculation treatment of leachate using poly-aluminum chloride (PAC) and alum, J. Hazard. Mater., 163, 650-656, 2009.

21. Box G.E.P., Hunter W.G., Hunter J.S., Statistics for Experimenters, John Wiley and Sons, New York, 291334, 1978.

22. Nemodurk A.A., Karalova Z.K., Analytical chemistry of boron, Jerusalem, Israel-Program for Scientific Translations, 1965.

23. Montgomery D.C., Design and Analysis of Experiments, 8th ed., John Wiley and Sons, New York, 575-651, 2013.

24. Ölmez T., The optimization of $\mathrm{Cr}$ (VI) reduction and removal by electrocoagulation using response surface methodology, J. Hazard. Mater, 162 (2), 1371-1378, 2009.

25. Yıldız N., Ateş Ç., Yılmaz M., Demir D., Yıldız A., Çalımlı A., Investigation of lichen based green synthesis of silver nanoparticles with response surface methodology, Green Processing and Synthesis, 3 (4), 259-270, 2014.

26. Joglekar A.M., May A.T., Product excellence through experimental design, Food Product and Development: From Concept to the Marketplace, 857-868, 1987.

27. Bashir M.J., Aziz H.A., Yusoff M.S., Adlan M.N., Application of response surface methodology (RSM) for optimization of ammoniacal nitrogen removal from semi-aerobic landfill leachate using ion exchange resin, Desalination, 254 (1), 154-161 2010. 
28. Kochkodan V., Darwish N.B., Hilal N., The Chemistry of Boron in Water, Elsevier, Amsterdam, 2015.

29. Wagman D.D., Evans W.H., Parker V.B., Schumm R. H., Halow I., The NBS tables of chemical thermodynamic properties. Selected values for inorganic and $\mathrm{C} 1$ and $\mathrm{C} 2$ organic substances in SI units,
National Standard Reference Data System, Gaithersburg, 1982.

30. Liu Z.H., Zuo C.F., Li S.Y., Synthesis and thermochemistry of $2 \mathrm{CaO} \cdot \mathrm{B} 2 \mathrm{O} 3 \cdot \mathrm{H} 2 \mathrm{O}$, Thermochimica acta, 424 (1), 59-62, 2004. 